\title{
Association of serum bilirubin level with lung function decline: a Korean community-based cohort study
}

\author{
Ah Young Leem¹, Ha Yan Kim², Young Sam Kim, Moo Suk Park', Joon Chang ${ }^{1}$ and Ji Ye Jung ${ }^{1 *}$
}

\begin{abstract}
Background: Bilirubin has been reported to be associated with respiratory diseases due to its antioxidant action. We aimed to evaluate the relationship between serum bilirubin concentration and annual lung function decline in the Korean general population.

Methods: The study included 7986 subjects aged 40-69 years from the Ansung-Ansan cohort database I (20012002)-III (2005-2006). We analyzed the relationships between serum bilirubin level and forced expiratory volume in $1 \mathrm{~s}\left(\mathrm{FEV}_{1}\right)$, forced vital capacity (FVC), FEV $/$ FVC, and mean forced expiratory flow between 25 and $75 \%$ of FVC $\left(\mathrm{FEF}_{25-75 \%}\right)$ at baseline, as well as the annual average changes in these lung parameters.

Results: The $\mathrm{FEV}_{1}, \mathrm{FVC}$, and $\mathrm{FEF}_{25-75 \%}$ were significantly associated with serum bilirubin levels after adjustment for age, sex, body mass index (BMI), and smoking status (all $P<0.001$ ). When stratified according to smoking status, these relationships were significant in never-smokers. Additionally, serum bilirubin level was negatively associated with the annual decline in $\mathrm{FEV}_{1}$ and $\mathrm{FVC}$, and positively associated with the annual decline in $\mathrm{FEV} / 1 / \mathrm{FVC}$ after adjustment for age, sex, BMl, baseline lung function, and smoking status (all $P<0.001$ ).

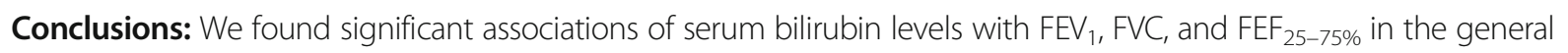
population, especially in never-smokers. Moreover, serum bilirubin levels were related with the annual decline in $\mathrm{FEV}_{1}$, $\mathrm{FVC}$, and $\mathrm{FEV}_{1} / \mathrm{FVC}$ ratio.
\end{abstract}

Keywords: Bilirubin, Lung function, Biomarker

\section{Background}

Serum total bilirubin is routinely measured to identify hepatobiliary and hemolytic diseases. Bilirubin is an end-product of heme degradation that has raised considerable interest over the last decade [1]. The benefits of elevated serum bilirubin are supported by animal and in vitro experiments showing antioxidant and anti-inflammatory properties [2]. In clinical studies, increased serum bilirubin has been associated with decreased risk for myocardial infarction, coronary artery disease, and stroke $[3,4]$ as well as lower incidence of lung cancer, chronic obstructive lung disease, and lung cancer mortality $[5,6]$. It has been suggested that bilirubin might

\footnotetext{
* Correspondence: STOPYES@yuhs.ac

${ }^{1}$ Division of Pulmonology, Department of Internal Medicine, Institute of Chest Disease, Severance Hospital, Yonsei University College of Medicine, 50-1 Yonsei-ro, Seodaemun-gu, Seoul 120-752, Republic of Korea Full list of author information is available at the end of the article
}

have protective effects in tissues exposed to the outer environment, such as the lungs, possibly by counteracting subclinical inflammation [3-6].

Only few previous studies have reported the relationship between serum bilirubin level and lung function parameters $[7,8]$. In the study by Curjuric et al., higher bilirubin levels were associated with higher forced expiratory volume in $1 \mathrm{~s}\left(\mathrm{FEV}_{1}\right) /$ forced volume capacity (FVC) ratio and forced expiratory flow at 25-75\% $\left(\mathrm{FEF}_{25-75 \%}\right)$ in the Swiss general population [7]. In the study by Apperley et al., serum bilirubin was positively related to $\mathrm{FEV}_{1}$ and negatively related to the annual decline in $\mathrm{FEV}_{1}$ in subjects with chronic obstructive pulmonary disease (COPD) with mild to moderate airflow limitation [8]. However, the relationships between bilirubin levels and decline in lung function parameters in the healthy general population have not been reported 
before. We aimed to evaluate the relationship between serum bilirubin concentration and annual lung function decline in the Korean general population.

\section{Methods}

\section{Study population}

The Ansung-Ansan cohort study is an ongoing prospective study that was started in 2001 with support from the National Genome Research Institute (Korea Centers for Disease Control and Prevention, Cheongju, Korea). The study is a part of the Korean Genome and Epidemiology Study, a large community-based epidemiologic survey to investigate chronic disease in Koreans. Detailed information on the study design and procedures has been published previously $[9,10]$. Each study comprised a population-based sample of male and female Koreans aged 40-69 y and from the same ethnic background, but cohort members were enrolled at the following 2 different sites: Ansan, which is an urban community with a population of 555,000 , and Ansung, which is a rural community including 133,000 residents, on the basis of the 2000 census. To enroll members for each cohort, the most efficient method was used on the basis of knowledge about characteristics of each community. For enrollment at the Ansan site, 10,957 eligible subjects were identified by telephone contact on the basis of a 2-stage cluster-sampling method with the information of a governing district called Dong and demographic characteristics. Similarly, Ansung members were recruited from 5 of 11 governing districts called Myon by using a cluster-sampling method, and as a result, 7192 eligible subjects were identified by mail or telephone contact and a door-to-door visit. For the baseline health examination from 18 June 2001 to 29 January 2003, 5020 participants (2523 men and 2497 women) from Ansan and 5018 (2239 men and 2779 women) from Ansung visited the Korea University Ansan Hospital and the Ajou University Medical Center, respectively. Cohort members were followed up biennially with a scheduled site visit for similar interviews and health examinations (I: 2001-2002, II: 2003-2004, III: 2005-2006).

In these subjects, initial data were obtained from 9785 subjects aged 40-69 years who participated in AnsungAnsan cohort I (2001-2002) and had valid lung function measurements without previous history of asthma, COPD, or hepatobiliary disease. Follow-up examinations are conducted biennially. Data from a baseline survey and two subsequent biennial surveys (I-III: 2001-2006) were analyzed in our study. Of the 9785 subjects in the study, 42 participants with total bilirubin concentrations $>1.75 \mathrm{mg} / \mathrm{dL}$ for women and $>2.34 \mathrm{mg} / \mathrm{dL}$ for men were excluded from the analysis. Finally, 7986 who underwent pulmonary function testing two times or more during I-III were used as the study population in this study (Fig. 1). The median follow-up duration was 3.6 years.

\section{Bilirubin measurement}

At baseline, venous blood samples were collected from eligible participants who originally consented, on the same day of lung function tests. Serum bilirubin was quantified by biochemical assays, performed by a central laboratory (Seoul Clinical Laboratories, Seoul, Korea) [11]. As described above, total bilirubin concentrations $>1.75 \mathrm{mg} / \mathrm{dL}$ for women and $>2.34 \mathrm{mg} / \mathrm{dL}$ for men were excluded from analysis. These limits represent concentrations 1 standard deviation (SD) above the mean serum total bilirubin associated with the most common variant of Gilbert syndrome, a benign hereditary cause of indirect hyperbilirubinemia [5].

\section{Lung function measurement}

Lung function was measured by spirometry (VMAX2130, SensorMedics Corporation, Yorba, CA, USA) at every visit (at baseline, and at the first and second follow-up visits).

Lung function decline was calculated as the difference in $\mathrm{FEV}_{1}$ measurements between the first and last measurement in each time interval divided by the number of years between measurements.

\section{Definitions}

We considered 'never-smokers' those individuals who declared that they never smoked before the study, 'former smokers' those smokers who declared that they had smoked before and stopped before the study, and 'continuous smokers' those smokers who declared active smoking in the study period.

\section{Statistical analysis}

We analyzed the relationships between bilirubin and $\mathrm{FEV}_{1}, \mathrm{FVC}, \mathrm{FEV}_{1} / \mathrm{FVC}$, and $\mathrm{FEF}_{25-75 \%}$ at baseline, and the annual average decline of these lung parameters. Participants were divided into quintiles of bilirubin

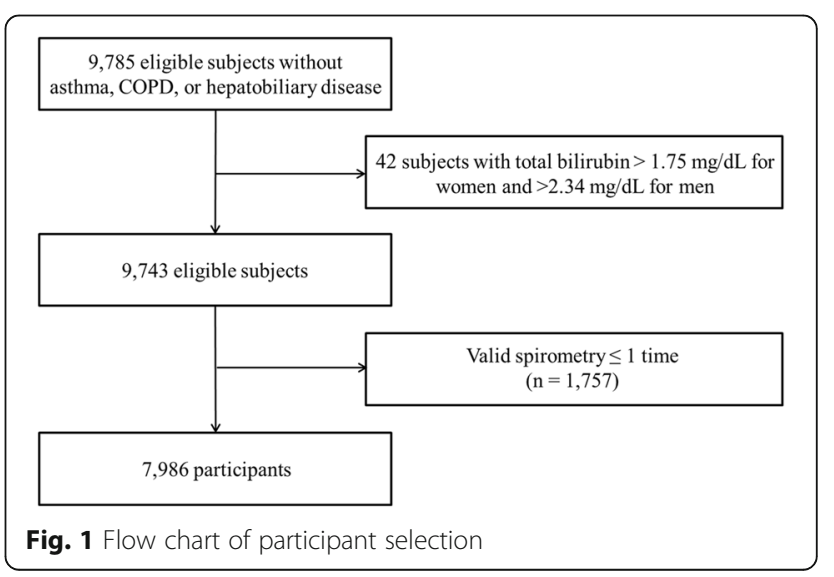


concentration, and baseline characteristics were compared using analysis of variance or Cochran-Mantel-Haenszel's test for trend. We performed the analysis using linear regression and bilirubin as a continuous variable rather than in quintiles. Linear regression with adjustment for age, sex, body mass index (BMI), and smoking status was used to examine the relationship between bilirubin and lung function parameters such as $\mathrm{FEV}_{1}, \mathrm{FVC}, \mathrm{FEV}_{1} / \mathrm{FVC}$ ratio, and $\mathrm{FEF}_{25-75 \%}$. The linear mixed model was used to evaluate the relationship between bilirubin and repeated-measured $\mathrm{FEV}_{1}, \mathrm{FVC}, \mathrm{FEV}_{1} / \mathrm{FVC}$, and $\mathrm{FEF}_{25-75 \%}$. All analyses were performed using $\mathrm{R}$ version 3.1 .3 (http:// www.R-project.org) and SAS (version 9.4, SAS Inc., Cary, NC, USA).

\section{Results}

\section{Baseline characteristics}

The demographics and clinical characteristics of the 7986 participants, stratified by quintiles of bilirubin concentration, are presented in Table 1. Age was negatively related to serum bilirubin concentration $(P<0.001)$. The proportion of male gender was positively related to serum bilirubin $(P<0.001)$. The proportion of continuous smokers and former smokers was increased while that of never-smokers was decreased toward higher quintiles of bilirubin concentration $(P<0.001)$. Lung function parameters of $\mathrm{FEV}_{1}, \mathrm{FVC}, \mathrm{FEV}_{1} / \mathrm{FVC}$, and $\mathrm{FEF}_{25-75 \%}$ were positively related to serum bilirubin level (all $P<0.001$ ) (Table 1).

\section{Associations of bilirubin with lung function parameters}

Table 2 shows the relationship between serum bilirubin and lung function according to smoking status, adjusted for covariates. When stratified by smoking status and adjusted for age, sex, and BMI, a positive relationship between bilirubin quintiles and $\mathrm{FEV}_{1}$ was present in continuous smokers $(P=0.048)$ and never-smokers $(P<0.001)$. When bilirubin was analyzed as a continuous variable, the positive relationship between bilirubin concentration and $\mathrm{FEV}_{1}$ was present only in never-smokers $(P<0.001)$. Lung function of FVC was positively related with bilirubin quintiles $(P=$ $0.018)$ and bilirubin level as continuous variable $(P=0.012)$ only in never-smokers. Positive relationship was observed between bilirubin quintile and $\mathrm{FEV}_{1} / \mathrm{FVC}$ ratio in never-smokers $(P=0.026)$. However, when bilirubin was analyzed as a continuous variable, the effect of bilirubin on $\mathrm{FEV}_{1} / \mathrm{FVC}$ ratio was not statistically significant. There was a significant positive relationship between bilirubin and $\mathrm{FEF}_{25-75 \%}$ in never-smokers $(P<0.001$ for quintile analysis, $P=0.001$ for continuous variable analysis).

The results of multivariate regression analysis for the effect of serum bilirubin levels on repeated measures of lung function are described in Table 3. The $\mathrm{FEV}_{1}$ (estimated mean $=0.12, P<0.001$ ), FVC (estimated mean $=$ $0.14, P<0.001$ ), and $\mathrm{FEF}_{25-75 \%}$ (estimated mean $=0.15$, $P<0.001$ ) were significantly associated with baseline bilirubin levels after adjustment for age, sex, BMI, and smoking status (Table 3). $\mathrm{FEV}_{1} / \mathrm{FVC}$ ratio tended to be related with baseline bilirubin level (estimated mean $=$ $0.51, P=0.0595)$.

Table 1 Baseline characteristics of the study participants by quintiles of bilirubin concentration

\begin{tabular}{|c|c|c|c|c|c|c|}
\hline \multirow[t]{2}{*}{ Parameters } & Quintile I & Quintile 2 & Quintile 3 & Quintile 4 & Quintile 5 & \multirow{2}{*}{$\begin{array}{l}P \text { for } \\
\text { Trend }\end{array}$} \\
\hline & $(n=1534)$ & $(n=1618)$ & $(n=1611)$ & $(n=1600)$ & $(n=1623)$ & \\
\hline Bilirubin, umol/L & $0.29 \pm 0.05$ & $0.42 \pm 0.03$ & $0.53 \pm 0.04$ & $0.68 \pm 0.05$ & $1.04 \pm 0.26$ & $<0.001$ \\
\hline Age, y & $53.9 \pm 9.0$ & $53.1 \pm 8.8$ & $51.7 \pm 8.6$ & $51.1 \pm 8.4$ & $49.9 \pm 8.4$ & $<0.001$ \\
\hline Sex, male & $401(26.14)$ & $616(38.07)$ & $750(46.55)$ & 959(59.94) & 1136(69.99) & $<0.001$ \\
\hline BMI & $24.5 \pm 3.2$ & $24.7 \pm 3.2$ & $24.7 \pm 3.2$ & $24.8 \pm 2.9$ & $24.6 \pm 2.9$ & 0.539 \\
\hline Smoking (baseline) & & & & & & $<0.001$ \\
\hline Continuous smoker & $311(20.27)$ & $400(24.72)$ & 409(25.39) & $454(28.38)$ & $422(26.00)$ & \\
\hline Former smoker & 117(7.63) & $169(10.44)$ & $241(14.96)$ & 307(19.19) & $452(27.85)$ & \\
\hline Never smoker & $1106(72.10)$ & 1049(64.83) & $961(59.65)$ & $839(52.44)$ & $749(46.15)$ & \\
\hline Pack-Y smoking & $24.9 \pm 18.6$ & $24.6 \pm 17.5$ & $23.4 \pm 15.8$ & $24.5 \pm 17.3$ & $20.1 \pm 15.8$ & $<0.001$ \\
\hline \multicolumn{7}{|l|}{ Lung function } \\
\hline $\mathrm{FEV}_{1}, \mathrm{~L}$ & $2.62 \pm 0.61$ & $2.78 \pm 0.66$ & $2.93 \pm 0.67$ & $3.06 \pm 0.69$ & $3.20 \pm 0.68$ & $<0.001$ \\
\hline FVC, L & $3.30 \pm 0.78$ & $3.51 \pm 0.85$ & $3.70 \pm 0.97$ & $3.84 \pm 0.87$ & $4.00 \pm 0.83$ & $<0.001$ \\
\hline $\mathrm{FEV}_{1} / \mathrm{FVC}, \%$ & $79.9 \pm 7.6$ & $79.7 \pm 7.6$ & $79.8 \pm 7.5$ & $80.2 \pm 7.3$ & $80.3 \pm 7.3$ & 0.044 \\
\hline $\mathrm{FEF}_{25-75 \%,} \mathrm{~L} / \mathrm{s}$ & $2.75 \pm 1.02$ & $2.87 \pm 1.03$ & $3.05 \pm 1.10$ & $3.20 \pm 1.16$ & $3.46 \pm 4.17$ & $<0.001$ \\
\hline
\end{tabular}

Notes: Data are presented as the number (\%) or the mean \pm standard deviation

Abbreviations: $B M I$ body mass index, $F E V$ forced expiratory volume in $1 \mathrm{~s}, F V C$ forced vital capacity, $F E F_{25-75 \%}$ forced expiratory flow between 25 and $75 \%$ of vital capacity 
Table 2 Relationship between serum bilirubin and lung function according to smoking status

\begin{tabular}{|c|c|c|c|c|c|c|c|c|}
\hline \multirow{2}{*}{$\begin{array}{l}\text { Lung function } \\
\text { parameters }\end{array}$} & \multicolumn{6}{|c|}{ Bilirubin (Quintiles) } & \multicolumn{2}{|c|}{ Bilirubin (Continuous) } \\
\hline & Quintile I & Quintile 2 & Quintile 3 & Quintile 4 & Quintile 5 & $P$ for Trend & $B \pm S E$ & $P$-value \\
\hline \multicolumn{9}{|l|}{$F E V_{1}, L$} \\
\hline Continuous smoker & $3.02 \pm 0.62$ & $3.17 \pm 0.66$ & $3.3 \pm 0.62$ & $3.44 \pm 0.57$ & $3.44 \pm 0.6$ & 0.048 & $0.09 \pm 0.05$ & 0.061 \\
\hline Former smoker & $3.04 \pm 0.69$ & $3.21 \pm 0.71$ & $3.33 \pm 0.64$ & $3.43 \pm 0.62$ & $3.48 \pm 0.61$ & 0.193 & $0.02 \pm 0.05$ & 0.619 \\
\hline Never smoker & $2.5 \pm 0.51$ & $2.57 \pm 0.53$ & $2.67 \pm 0.55$ & $2.77 \pm 0.59$ & $2.95 \pm 0.64$ & $<0.001$ & $0.10 \pm 0.03$ & $<0.001$ \\
\hline \multicolumn{9}{|l|}{$\mathrm{FVC}, \mathrm{L}$} \\
\hline Continuous smoker & $3.95 \pm 0.83$ & $4.19 \pm 0.79$ & $4.3 \pm 0.72$ & $4.37 \pm 0.68$ & $4.38 \pm 0.67$ & 0.262 & $0.04 \pm 0.06$ & 0.441 \\
\hline Former smoker & $3.94 \pm 0.75$ & $4.08 \pm 0.79$ & $4.21 \pm 0.69$ & $4.37 \pm 0.69$ & $4.32 \pm 0.64$ & 0.454 & $-0.02 \pm 0.06$ & 0.772 \\
\hline Never smoker & $3.08 \pm 0.6$ & $3.16 \pm 0.64$ & $3.31 \pm 0.98$ & $3.39 \pm 0.73$ & $3.61 \pm 0.79$ & 0.018 & $0.10 \pm 0.04$ & 0.012 \\
\hline \multicolumn{9}{|l|}{$\mathrm{FEV}_{1} / \mathrm{FVC}, \%$} \\
\hline Continuous smoker & $77.11 \pm 7.71$ & $76.42 \pm 8.51$ & $77.39 \pm 7.63$ & $78.54 \pm 7.97$ & $79.35 \pm 7.48$ & 0.205 & $1.02 \pm 0.64$ & 0.109 \\
\hline Former smoker & $76.98 \pm 9.09$ & $77.85 \pm 8.49$ & $78.26 \pm 8.01$ & $78.88 \pm 6.54$ & $79.6 \pm 7.27$ & 0.516 & $0.52 \pm 0.65$ & 0.423 \\
\hline Never smoker & $81.36 \pm 6.68$ & $81.62 \pm 6.39$ & $81.53 \pm 6.37$ & $81.99 \pm 6.28$ & $81.96 \pm 6.16$ & 0.027 & $0.76 \pm 0.41$ & 0.061 \\
\hline \multicolumn{9}{|l|}{$\mathrm{FEF}_{25-75 \%,} \mathrm{~L} / \mathrm{s}$} \\
\hline Continuous smoker & $2.88 \pm 1.15$ & $2.98 \pm 1.23$ & $3.16 \pm 1.21$ & $3.43 \pm 1.34$ & $3.97 \pm 8.54$ & 0.063 & $0.53 \pm 0.39$ & 0.176 \\
\hline Former smoker & $2.83 \pm 1.14$ & $3.05 \pm 1.18$ & $3.26 \pm 1.3$ & $3.4 \pm 1.19$ & $3.53 \pm 1.27$ & 0.267 & $0.06 \pm 0.10$ & 0.534 \\
\hline Never smoker & $2.77 \pm 0.97$ & $2.85 \pm 0.91$ & $2.97 \pm 0.95$ & $3.1 \pm 1.02$ & $3.28 \pm 1.06$ & $<0.001$ & $0.18 \pm 0.06$ & 0.001 \\
\hline
\end{tabular}

Notes: Data are presented as the mean \pm standard deviation. Bilirubin was analyzed across quintiles and as a continuous variable

P-value for linear trend analysis adjusted for age, sex, and body mass index

Abbreviations: SE standard error, $F E V_{1}$ forced expiratory volume in $1 \mathrm{~s}, F V C$ forced vital capacity, $F E F_{25-75 \%}$ forced expiratory flow between 25 and $75 \%$ of vital capacity

\section{Bilirubin and lung function decline}

Figures 2, 3, and 4 show the relationship between bilirubin and the decline of lung function parameters. Higher bilirubin concentration was significantly related to reduced rate of annual decline in $\mathrm{FEV}_{1}$ (Fig. 2a) and FVC (Fig. 3a) (all $P<0.001$ ). After adjustment for age, sex, BMI, baseline lung function, and smoking status, this inverse relationship persisted (all $P<0.001$ ) (Figs. $2 \mathrm{~b}$ and $3 \mathrm{~b}$ ). The annual change in $\mathrm{FEV}_{1} / \mathrm{FVC}$ ratio was positively associated with bilirubin concentration in univariate and multivariate adjusted analysis (all $P<0.001$ ) (Fig. 4a, b).

\section{Discussion}

In this population-based study, serum bilirubin was positively related with $\mathrm{FEV}_{1}, \mathrm{FVC}$, and $\mathrm{FEF}_{25-75 \%}$. When stratified according to smoking status, these relationships were prominent in never-smokers. Furthermore, bilirubin concentration was inversely related to the rate of decline

Table 3 Multivariate regression analysis for the relationship between bilirubin and pulmonary lung function

\begin{tabular}{|c|c|c|c|c|c|c|}
\hline \multirow{2}{*}{$\begin{array}{l}\text { Lung function } \\
\text { parameters }\end{array}$} & \multirow[t]{2}{*}{ Bilirubin } & \multicolumn{5}{|c|}{ Bilirubin category } \\
\hline & & Quintile 1 & Quintile 2 & Quintile 3 & Quintile 4 & Quintile 5 \\
\hline \multicolumn{7}{|l|}{$\mathrm{FEV}_{1}, \mathrm{~L}$} \\
\hline Estimated mean (SE) & $0.12(0.02)$ & ref & $0.03(0.02)$ & $0.06(0.02)$ & $0.07(0.02)$ & $0.11(0.02)$ \\
\hline$P$-value & $<0.001$ & & 0.154 & 0.002 & $<0.001$ & $<0.001$ \\
\hline \multicolumn{7}{|l|}{$F V C, L$} \\
\hline Estimated mean (SE) & $0.14(0.02)$ & ref & $0.05(0.02)$ & $0.10(0.02)$ & $0.09(0.02)$ & $0.13(0.02)$ \\
\hline$P$-value & $<0.001$ & & 0.018 & $<0.001$ & $<0.001$ & $<0.001$ \\
\hline \multicolumn{7}{|l|}{$\mathrm{FEV}_{1} / \mathrm{FVC}, \%$} \\
\hline Estimated mean (SE) & $0.51(0.27)$ & ref & $-0.39(0.25)$ & $-0.47(0.25)$ & $0.22(0.25)$ & $0.26(0.25)$ \\
\hline$P$-value & 0.059 & & 0.113 & 0.055 & 0.371 & 0.307 \\
\hline \multicolumn{7}{|l|}{$\mathrm{FEF}_{25-75 \%,} \mathrm{~L} / \mathrm{s}$} \\
\hline Estimated mean (SE) & $0.15(0.04)$ & ref & $0.01(0.05)$ & $0.03(0.05)$ & $0.11(0.05)$ & $0.20(0.05)$ \\
\hline$P$-value & $<0.001$ & & 0.857 & 0.575 & 0.022 & $<0.001$ \\
\hline
\end{tabular}

Notes: Data were adjusted for age, sex, body mass index, and smoking status (current smoker, former smoker, and never-smoker) 

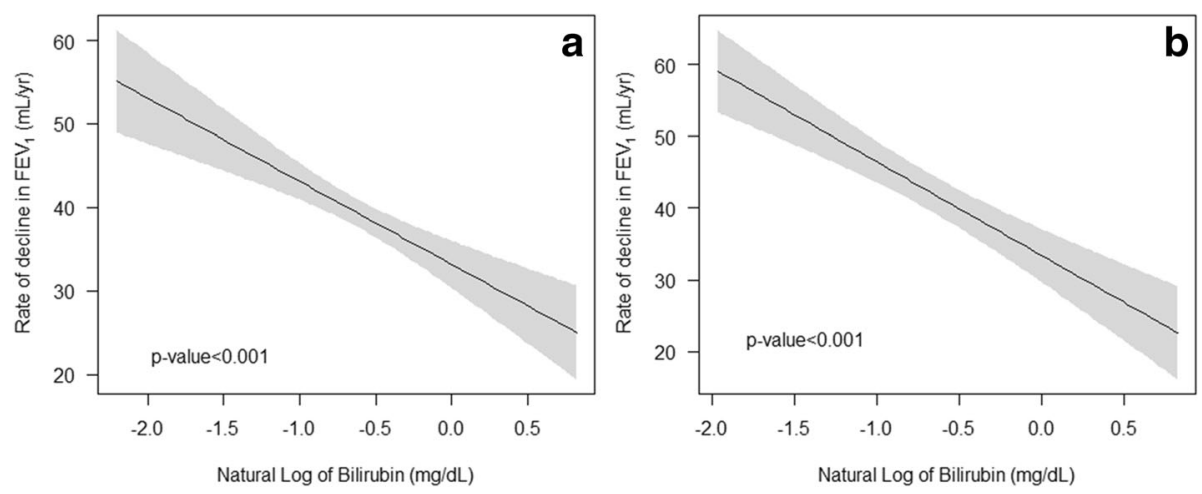

Fig. 2 Average annual decline of $\mathrm{FEV}_{1}$ relative to the natural logarithm of serum bilirubin. Notes: Bilirubin is expressed in mg/dL in parentheses. a Univariate relationship (linear regression coefficienct $=-9.93$ ) and $\mathbf{b}$ relationship adjusted for age, sex, BMI, FEV 1 at baseline, and smoking status (current smoker, former smoker, and never-smoker)(linear regression coefficienct $=-13.09$ ). Abbreviations: BMI, body mass index; FEV , forced expiratory volume in $1 \mathrm{~s}$

in $\mathrm{FEV}_{1}$ and $\mathrm{FVC}$ (mL/year). The annual decline in $\mathrm{FEV}_{1} /$ FVC ratio was positively associated with bilirubin concentration. This is the first longitudinal study investigating the relationships between bilirubin levels and the changes of lung function parameters based on a general population-based cohort.

The beneficial effects of serum bilirubin on respiratory outcomes have been reported in several studies $[5,6,12]$. In a previous study by Temme et al., high serum bilirubin was associated with lower cancer mortality, including that of lung cancer [6]. In a study by Horsfall et al., relatively higher levels of bilirubin were associated with a lower risk of respiratory diseases such as lung cancer and COPD, and all-cause mortality among patients with normal-range bilirubin levels in primary care practices of United Kingdom [5]. It was the first large epidemiologic study to find that bilirubin concentration is negatively associated with
COPD incidence. In a report by Brown et al., higher bilirubin was associated with a significantly lower hazard for acute exacerbation of COPD [12]. These results of previous studies suggest that bilirubin might have protective effects in lung tissues, possibly by counteracting subclinical inflammation. The results of our study are in line with previous results in that they showed the lung protective effect of bilirubin.

Only few studies about the relationship between bilirubin levels and lung function have been reported [7, 8]. Curjuric et al. showed that high bilirubin levels were significantly associated with higher $\mathrm{FEV}_{1} / \mathrm{FVC}$ and $\mathrm{FEF}_{25-75 \%}$ in the Swiss general population sample [7]. In that cross-sectional study, decreased serum bilirubin levels were associated with increased risk of COPD [7]. It was the only study that investigated the relationships between serum bilirubin and lung function in a healthy
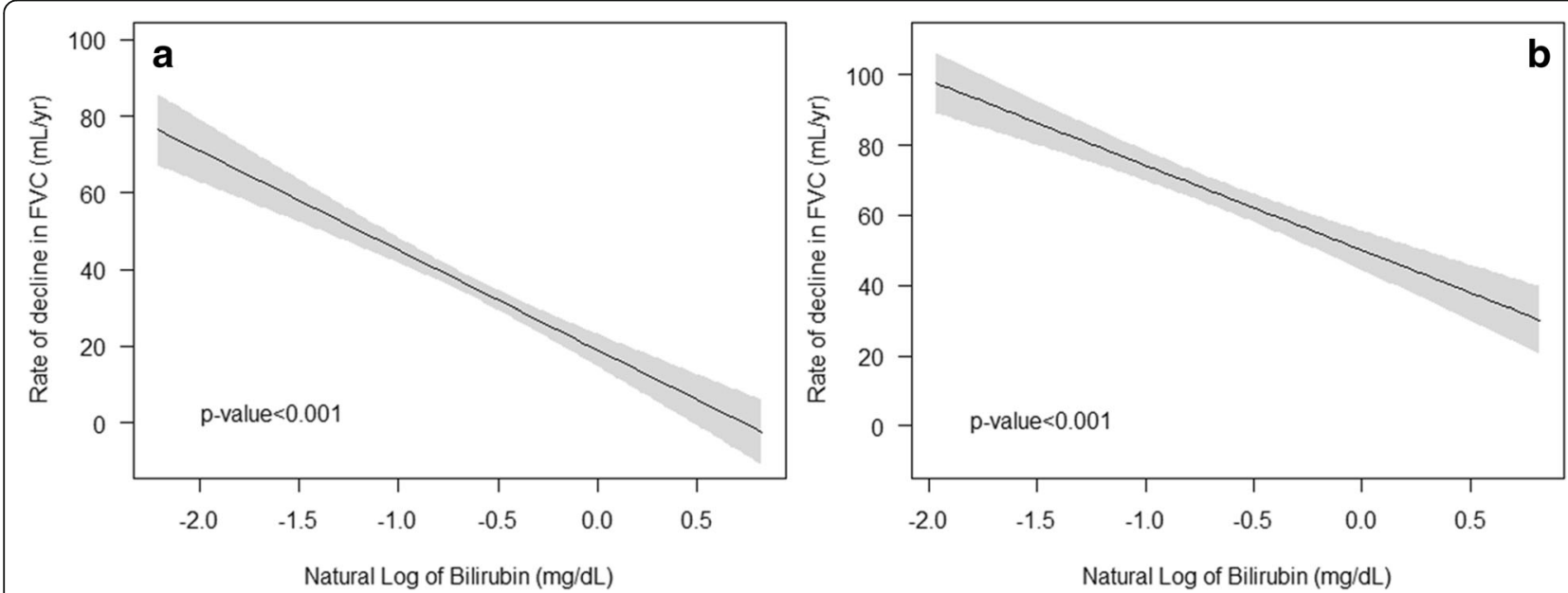

Fig. 3 Average annual decline of FVC relative to the natural logarithm of serum bilirubin. Notes: Bilirubin is expressed in mg/dL in parentheses. a Univariate relationship (linear regression coefficienct $=-26.04$ ) and $\mathbf{b}$ relationship adjusted for age, sex, BMI, FVC at baseline, and smoking status (current smoker, former smoker, and never smoker)(linear regression coefficienct $=-24.19$ ). Abbreviations: BMl, body mass index; FVC, forced vital capacity 

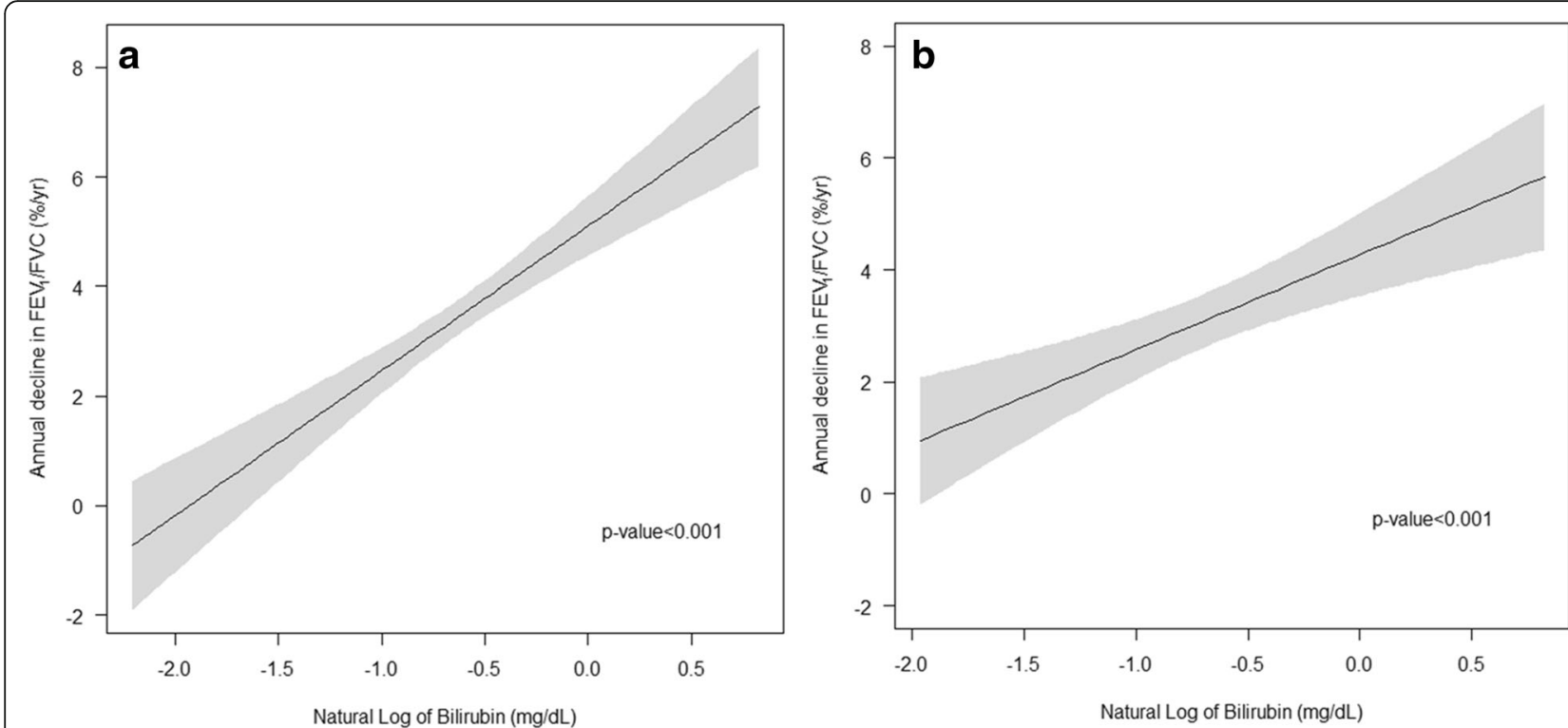

Fig. 4 Average annual changes in $\mathrm{FEV}_{1} / \mathrm{FVC}$ ratio relative to the natural logarithm of serum bilirubin. Notes: Bilirubin is expressed in mg/dL in parentheses. a Univariate relationship (linear regression coefficienct $=2.64$ ) and $\mathbf{b}$ relationship adjusted for age, sex, BMI, FEV ${ }_{1} / \mathrm{FVC}$ ratio at baseline, and smoking status (current smoker, former smoker, and never-smoker)(linear regression coefficienct = 1.69). Abbreviations: BMI, body mass index; $\mathrm{FEV}_{1}$, forced expiratory volume in $1 \mathrm{~s}$; FVC, forced vital capacity

general population. For $\mathrm{FEF}_{25-75 \%}$, the results of that study were consistent with ours. The significant associations with $\mathrm{FEF}_{25-75 \%}$ might be related to the inverse relationship of bilirubin concentrations with small airway obstruction. However, both $\mathrm{FEV}_{1}$ and FVC were positively related to bilirubin concentration in our study, inconsistent with the results of Curjuric et al. in which bilirubin concentration was not significantly related to $\mathrm{FEV}_{1}$ or FVC. The differences in proportion of sex, distribution of smoking status, covariates adjusted may have resulted in different outcomes. In another study, Apperley et al. reported that serum bilirubin was positively related to $\mathrm{FEV}_{1}$ and negatively related to the annual decline in $\mathrm{FEV}_{1}$ in patients with mild to moderate COPD [8]. This was the only study that evaluated the relationships between serum bilirubin levels and the decline of $\mathrm{FEV}_{1}$ in patients with COPD [8]. We extended these results by demonstrating that serum bilirubin levels relate to $\mathrm{FEV}_{1}$ and $\mathrm{FEV}_{1}$ decline in a large community-based cohort of general population. Furthermore, we showed the relationships between serum bilirubin levels and other lung function parameters such as FVC, $\mathrm{FEV}_{1} / \mathrm{FVC}$ ratio, and $\mathrm{FEF}_{25-75 \%}$.

One study reported the relationships between serum inflammatory biomarkers, including total bilirubin, and COPD in never-smokers in the Korean population [13]. In that study, serum bilirubin concentration was not significantly associated with the presence of COPD in never-smokers [13]. However, the limitation of the study is that the sample size was small, and the relationship of bilirubin level with lung function was not assessed.

The possible related biological mechanisms of the role of bilirubin on lung function in COPD patients have been reported [14-17]. When heme is degraded to biliverdin by heme oxygenase, the production of bilirubin begins [14]. Biliverdin is subsequently reduced to bilirubin by biliverdin reductase [14]. Heme oxygenase-1 (HO-1), the inducible isoform of heme oxygenase expressed in type 2 pneumocytes and alveolar macrophages in the lung, has been reported to be up-regulated by oxidative stress and hypoxia $[15,16]$. Genomic studies have found that the relative gene expression of heme oxygenase and biliverdin reductase is high in lung tissue [17]. The $\mathrm{HO}-1$ gene contains a variable number of GT nucleic acid repeats in its flanking region, and individuals with fewer GT repeats have higher serum bilirubin concentrations and a lower risk of COPD $[18,19]$.

In COPD, oxidative stress is affected by both endogenously produced oxidants and exogenous sources such as smoking. An animal study using animal model supported a protective effect of increased bilirubin against respiratory injury by environmental stressors [20]. In the study by Sedlak et al., bilirubin had a greater affinity in preventing oxidation of lipids, and inhibition of bilirubin synthesis resulted in significant increases in lipid peroxidation products [20].

In human lungs, it is reported that oxidant-antioxidant imbalance is associated with airways obstruction, and 
altered oxidant-antioxidant balance in patients with COPD increases in parallel with the severity of the disease [21]. Repine et al. reported that lipid peroxidation causes damage to multiple cell membrane components and impairs cell structure and permeability [22]. Patients with COPD have higher levels of lipid peroxidation products in sputum [23], and serum levels of these products are higher in patients with severe airflow limitation compared with those with moderate limitation [24]. Based on these results, we suggest that bilirubin might protect the lungs by inhibiting lipid peroxidation [21-24].

To our knowledge, this is the first longitudinal study that analyzed the relationships between bilirubin levels and changes in lung function parameters in the healthy general population. The study was conducted in a prospective, large cohort using various spirometric measures. However, the study also has several limitations. First, the follow-up period was relatively short, yet the AnsungAnsan cohort study is still ongoing. We expect to be able to analyze the data further with longer follow-up. Second, we used pre-bronchodilator spirometric values instead of post-bronchodilator values. Third, serum bilirubin concentration was only measured at baseline and it is unsure if bilirubin level was stable during the follow-up period. Therefore, the relationships between the changes of bilirubin concentration and lung function decline could not be analyzed. Lastly, the information on alcohol consumption, previous drug intake, or diet which can affect bilirubin level was not fully investigated in this cohort study.

\section{Conclusions}

We found significant positive associations of serum bilirubin levels with $\mathrm{FEV}_{1}, \mathrm{FVC}$, and $\mathrm{FEF}_{25-75 \%}$ in the general population, especially in never-smokers after adjustment of age, sex, BMI, and smoking status. Furthermore, serum bilirubin concentration was also significantly related to the annual changes in $\mathrm{FEV}_{1}, \mathrm{FVC}$, and $\mathrm{FEV}_{1} / \mathrm{FVC}$ ratio. Further research is needed to investigate causal associations between bilirubin levels and lung function.

\section{Abbreviations}

BMI: Body mass index; COPD: Chronic obstructive pulmonary disease;

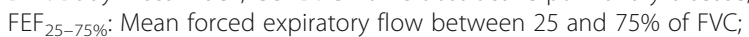
$\mathrm{FEV}_{1}$ : Forced expiratory volume in $1 \mathrm{~s}$; FVC: Forced vital capacity; SD: Standard deviation

\section{Funding}

This research was supported by Basic Science Research Program through the National Research Foundation of Korea (NRF) funded by the Ministry of Education (2016R1D1A1B03933125).

\section{Availability of data and materials}

The datasets used and/or analysed during the current study are available from the the Ansung-Ansan cohort database (http://www.nih.go.kr/NIH NEW/contents/NihKrContentView.jsp?cid=\%2026,458\&viewType $\% 20=\% 20 C D C$ \&menulds\%20=\%20HOME005-MNU2016-MNU1010-MNU1543) on reasonable request.

\section{Authors' contributions}

AYL contributed to data acquisition and analysis, and drafting of the article. HYK contributed to data analysis. MSP and JC contributed to conception and design. YSK contributed to data analysis and critical revision of the paper. JYJ contributed to conception, design, and critical revision of the paper. All authors agreed to be accountable for all aspects of the work. All authors read and approved the final manuscript.

\section{Ethics approval and consent to participate}

The Korea Centers for Disease Control and Prevention obtained written informed consent from all participants, and the Institutional Review Board of Severance Hospital approved this study protocol (4-2015-1071).

\section{Competing interests}

The authors declare that they have no competing interests.

\section{Publisher's Note}

Springer Nature remains neutral with regard to jurisdictional claims in published maps and institutional affiliations.

\section{Author details}

${ }^{1}$ Division of Pulmonology, Department of Internal Medicine, Institute of Chest Disease, Severance Hospital, Yonsei University College of Medicine, 50-1 Yonsei-ro, Seodaemun-gu, Seoul 120-752, Republic of Korea.

${ }^{2}$ Biostatistics Collaboration Unit, Department of Biomedical Systems Informatics, Yonsei University College of Medicine, Seoul, Republic of Korea.

Received: 30 March 2018 Accepted: 14 May 2018

Published online: 23 May 2018

\section{References}

1. Kronenberg F. Association of bilirubin with cardiovascular outcomes: more hype than substance? Circ Cardiovasc Genet. 2010;3(4):308-10.

2. Stocker R, Yamamoto Y, McDonagh AF, Glazer AN, Ames BN. Bilirubin is an antioxidant of possible physiological importance. Science. 1987;235(4792):1043-6.

3. Schwertner HA, Vitek L. Gilbert syndrome, UGT1A1*28 allele, and cardiovascular disease risk: possible protective effects and therapeutic applications of bilirubin. Atherosclerosis. 2008;198(1):1-11.

4. Lin JP, Vitek L, Schwertner HA. Serum bilirubin and genes controlling bilirubin concentrations as biomarkers for cardiovascular disease. Clin Chem. 2010;56(10):1535-43.

5. Horsfall L, Rait G, Walters K, Swallow DM, Pereira SP, Nazareth I, et al. Serum bilirubin and risk of respiratory disease and death. JAMA. 2011;305(7):691-7.

6. Temme EH, Zhang J, Schouten EG, Kesteloot H. Serum bilirubin and 10-year mortality risk in a Belgian population. Cancer Causes Control. 2001;12(10):887-94.

7. Curjuric I, Imboden M, Adam M, Bettschart RW, Gerbase MW, Kunzli N, et al. Serum bilirubin is associated with lung function in a Swiss general population sample. Eur Respir J. 2014;43(5):1278-88.

8. Apperley S, Park HY, Holmes DT, Man SF, Tashkin D, Wise RA, et al. Serum bilirubin and disease progression in mild COPD. Chest. 2015;148(1):169-75.

9. Baik I, Cho NH, Kim SH, Han BG, Shin C. Genome-wide association studies identify genetic loci related to alcohol consumption in Korean men. Am J Clin Nutr. 2011;93(4):809-16.

10. Leem AY, Park B, Kim YS, Jung JY, Won S. Incidence and risk of chronic obstructive pulmonary disease in a Korean community-based cohort. Int J Chron Obstruct Pulmon Dis. 2018;13:509-17.

11. Ha KH, Kim HC, Park S, Ihm SH, Lee HY. Gender differences in the association between serum gamma-glutamyltransferase and blood pressure change: a prospective community-based cohort study. J Korean Med Sci. 2014;29(10):1379-84

12. Brown KE, Sin DD, Voelker H, Connett JE, Niewoehner DE, Kunisaki KM Serum bilirubin and the risk of chronic obstructive pulmonary disease exacerbations. Respir Res. 2017:18(1):179.

13. Lee H, Hong Y, Lim MN, Bak SH, Kim MJ, Kim K, et al. Inflammatory biomarkers and radiologic measurements in never-smokers with COPD: a cross-sectional study from the CODA cohort. Chron Respir Dis. 2017; https://doi.org/10.1177/1479972317736293.1479972317736293.

14. Chen W, Maghzal GJ, Ayer A, Suarna C, Dunn LL, Stocker R. Absence of the biliverdin reductase-a gene is associated with increased endogenous oxidative stress. Free Radic Biol Med. 2018;115:156-65. 
15. Carter EP, Garat C, Imamura M. Continual emerging roles of HO-1: protection against airway inflammation. Am J Physiol Lung Cell Mol Physiol. 2004;287(1):L24-5.

16. Fredenburgh LE, Perrella MA, Mitsialis SA. The role of heme oxygenase-1 in pulmonary disease. Am J Respir Cell Mol Biol. 2007;36(2):158-65.

17. Burren OS, Adlem EC, Achu_than P, Christensen M, Coulson RM, Todd JA. T1DBase: update 2011, organization and presentation of large-scale data sets for type 1 diabetes research. Nucleic Acids Res. 2011;39(Database issue): D997-1001.

18. D'Silva S, Borse V, Colah RB, Ghosh K, Mukherjee MB. Association of (GT)n repeats promoter polymorphism of heme oxygenase-1 gene with serum bilirubin levels in healthy Indian adults. Genet Test Mol Biomarkers. 2011;15(4):215-8

19. Yamada N, Yamaya M, Okinaga S, Nakayama K, Sekizawa K, Shibahara S, et al. Microsatellite polymorphism in the heme oxygenase-1 gene promoter is associated with susceptibility to emphysema. Am J Hum Genet. 2000;66(1):187-95.

20. Sedlak TW, Saleh M, Higginson DS, Paul BD, Juluri KR, Snyder SH. Bilirubin and glutathione have complementary antioxidant and cytoprotective roles. Proc Natl Acad Sci U S A. 2009;106(13):5171-6

21. Singh S, Verma SK, Kumar S, Ahmad MK, Nischal A, Singh SK, et al. Evaluation of oxidative stress and antioxidant status in chronic obstructive pulmonary disease. Scand J Immunol. 2017;85(2):130-7.

22. Repine JE, Bast A, Lankhorst I. Oxidative stress in chronic obstructive pulmonary disease. Oxidative Stress Study Group Am J Respir Crit Care Med. 1997:156(2 Pt 1):341-57.

23. Nowak D, Kasielski M, Antczak A, Pietras T, Bialasiewicz P. Increased content of thiobarbituric acid-reactive substances and hydrogen peroxide in the expired breath condensate of patients with stable chronic obstructive pulmonary disease: no significant effect of cigarette smoking. Respir Med. 1999;93(6):389-96.

24. Kluchova Z, Petrasova D, Joppa P, Dorkova Z, Tkacova R. The association between oxidative stress and obstructive lung impairment in patients with COPD. Physiol Res. 2007;56(1):51.

\section{Ready to submit your research? Choose BMC and benefit from}

- fast, convenient online submission

- thorough peer review by experienced researchers in your field

- rapid publication on acceptance

- support for research data, including large and complex data types

- gold Open Access which fosters wider collaboration and increased citations - maximum visibility for your research: over $100 \mathrm{M}$ website views per year 